\title{
Cardiovascular effects of apnoea in preterm infants
}

\author{
C. NICHOLAS STORRS
}

From the Research Institute of the Hospital for Sick Children, Toronto, Ontario, Canada

SUMMARY Cardiovascular reflex responses have been studied in 9 newborn preterm infants with apnoeic episodes and in 2 preterm infants with periodic breathing. Respiration, blood pressure, heart rate, and peripheral blood flow were simultaneously recorded. Peripheral blood flow was measured in the leg by venous occlusion plethysmography. During apnoea, bradycardia and peripheral vasoconstriction occur. There is little change in blood pressure though pulse pressure increases. No cardiovascular changes were seen before the onset of apnoea. Periodic breathing had little effect on peripheral blood flow. Preterm infants with gestations as low as 27 weeks apparently have well developed chemoreceptor reflexes which would tend to preserve blood supply to the brain during conditions of hypoxia.

The incidence of apnoea unrelated to disease in preterm infants varies from $25 \%$ in infants of less than $2500 \mathrm{~g}$ to $84 \%$ in infants of less than $1000 \mathrm{~g}$ at birth (Daily et al., 1969; Alden et al., 1972). Apnoea may also occur in association with the respiratory distress syndrome and other respiratory problems, intracranial haemorrhage, infection, or metabolic disturbances.

Clinically, after the onset of apnoea the infant may become bradycardic, cyanosed, and hypotonic. Apnoea may terminate spontaneously, but with increasing duration, stimulation or resuscitation is needed to restart breathing. Though it is not certain to what extent recurrent apnoea may lead to brain damage, it seems obvious that the risk will increase with prolonged apnoea leading to asphyxia.

The risk of brain damage will depend not only on the degree of cerebral hypoxia but also on the maintenance of an adequate cerebral circulation (Dawes, 1968). In animals under conditions of hypoxia or diving under water, the cerebral circulation is maintained at the expense of the rest of the systemic circulation (Scholander, 1960). Is this true for the immature infant? Girling (1972) showed that at least babies' blood pressure (BP) was initially maintained during apnoea, though it fell when the infant's condition was terminal.

This paper reports a study of the nature and timing of the cardiovascular reflex response to apnoea, and secondarily an attempt to determine whether any cardiovascular events preceded apnoea to exclude cardiovascular causes for apnoea that have been reported in animals (Grunstein et al., 1974).

Received 14 October 1976

\section{Materials and methods}

Nine infants were studied during the first 8 days of life in whom apnoea had occurred while recovering from the respiratory distress syndrome or transient tachypnoea. Apnoea is defined as cessation of spontaneous respiratory effort for 5 seconds or more. In this study apnoea is reported only when it lasted long enough to produce cardiovascular changes. One infant (Case 6) had episodes of apparent hypoventilation rather than complete apnoea. 2 infants with periodic breathing were also studied at 13 and 52 days of age.

The clinical details of patients are given in Table 1. Case 9 was being weaned off artificial ventilation and was alternately on positive pressure ventilation and continuous positive airways pressure (CPAP). In this case the apnoea occurring during CPAP was studied.

Infants were studied in incubators at a neutral environmental temperature and with controlled supplemental oxygen to maintain arterial oxygen tension between 50 and $80 \mathrm{mmHg} .(6 \cdot 7$ and $10 \cdot 6$ $\mathrm{kPa})$. They were normoglycaemic and in normal acid-base and electrolyte balance. Respiration, electrocardiogram (ECG) direct aortic BP (Bell \& Howell Blood Pressure Transducer, Type 4-327-0109) and peripheral blood flow were simultaneously recorded on a Hewlett Packard 4 channel recorder. Respiratory movement was recorded from a pair of magnetometers applied anteroposteriorly at the level of the epigastrium. Heart rate was calculated from either the ECG or BP trace by measuring the RR or peak systolic pressure intervals. BP in the lower abdominal aorta was measured in 5 infants (Cases 
Table 1 Clinical details of babies studied

\begin{tabular}{|c|c|c|c|c|c|c|}
\hline Case no. & Sex & Birthweight $(g)$ & Gestation (w) & Diagnosis & Age studied $(d)$ & Study conditions \\
\hline $\begin{array}{l}1 \\
2 \\
3\end{array}$ & $\begin{array}{l}\mathbf{M} \\
\mathbf{F} \\
\mathbf{M}\end{array}$ & $\begin{array}{r}975 \\
1050 \\
1670\end{array}$ & $\begin{array}{l}27 \\
28 \\
30\end{array}$ & $\begin{array}{l}\text { Apnoeic episodes; mild RDS } \\
\text { Apnoeic episodes; transient tachypnoea } \\
\text { Apnoeic episodes, fetal distress, and } \\
\text { birth asphyxia; transient tachypnoea }\end{array}$ & $\begin{array}{l}2 \\
1 \\
8\end{array}$ & CPAP $3-4 \mathrm{~cm} \mathrm{H}_{2} \mathrm{O}$ \\
\hline 4 & $\mathbf{F}$ & 1050 & 28 & Apnoeic episodes; transient tachypnoea & 2 & \\
\hline $\begin{array}{l}5 \\
6\end{array}$ & $\begin{array}{l}\mathbf{M} \\
\mathbf{F}\end{array}$ & $\begin{array}{l}1235 \\
1880\end{array}$ & $\begin{array}{l}29 \\
33\end{array}$ & $\begin{array}{l}\text { Apnoeic episodes; transient tachypnoea } \\
\text { Hypoventilation episodes; severe RDS }\end{array}$ & $\begin{array}{l}2 \\
3\end{array} 3$ & $\begin{array}{l}\text { Phototherapy } \\
\text { Phototherapy; }\end{array}$ \\
\hline $\begin{array}{l}7 \\
8\end{array}$ & $\begin{array}{l}\mathbf{M} \\
\mathbf{F}\end{array}$ & $\begin{array}{r}1680 \\
910\end{array}$ & $\begin{array}{l}34 \\
27\end{array}$ & $\begin{array}{l}\text { Apnoeic episodes; RDS } \\
\text { Apnoeic episodes; birth asphyxia; }\end{array}$ & 3 & CPAP $1-2 \mathrm{~cm} \mathrm{H} \mathrm{H}_{2} \mathrm{O}$ \\
\hline 9 & $\mathbf{M}$ & 2150 & 34 & $\begin{array}{l}\text { severe RDS } \\
\text { Apnoeic episodes; RDS }\end{array}$ & $\begin{array}{l}2 \\
2\end{array}$ & $\begin{array}{l}\text { CPAP } 3 \mathrm{~cm} \mathrm{H}_{2} \mathrm{O} \\
\text { Ventilator/CPAP } \\
\quad 5 \mathrm{~cm} \text {, alternately }\end{array}$ \\
\hline $\begin{array}{l}10 \\
11\end{array}$ & $\begin{array}{l}\mathbf{F} \\
\mathbf{F}\end{array}$ & $\begin{array}{l}1470 \\
1200\end{array}$ & $\begin{array}{l}32 \\
30\end{array}$ & $\begin{array}{l}\text { Periodic breathing } \\
\text { Periodic breathing }\end{array}$ & $\begin{array}{l}13 \\
52\end{array}$ & \\
\hline
\end{tabular}

$\mathbf{R D S}=$ respiratory distress syndrome; $\mathbf{C P A P}=$ continuous positive airways pressure.

2,6-9) through an umbilical arterial catheter already placed for clinically indicated blood gas and other biochemical monitoring. Systolic BP in 5 infants was measured in the leg during normal breathing using venous occlusion plethysmography (Levison et al., 1966) (Plethysmograph, Parks Model No. 270). Neither respiratory movement nor BP was recorded in Case 1.

Blood flow in the right leg was measured in 8 infants using a modified Whitney mercury-in-rubber strain gauge (Whitney, 1949, 1953) as previously described from this centre (Kidd et al., 1966, Powers and Swyer, $1975 \mathrm{a}, \mathrm{b})$. The gauge was initially calibrated at room temperature at a tension of $12 \mathrm{~g}$ and then applied to the limb. The shift in baseline due to the rise in temperature was compensated either by adjusting the tension of the gauge or by electrical means. We have established that change in temperature over the range from room to body temperature causes baseline shift but no change in calibration. Similarly, calibration is not altered by changes in tension within the limits used in the study.

Venous occlusion plethysmography gives an intermittent measure of flow. Thus 5-7 flow measurements were made in rapid succession allowing sufficient time (5-10 seconds) for the baseline to stabilize between each measurement. It was seldom possible to obtain more than one or two flow measurements during a given period of apnoea. Since peripheral flow may fluctuate even during regular breathing the individual flow measurement during apnoea has been compared only with the average of the group of flow measurements immediately before onset of apnoea, which in every case except one was within 5 minutes. In one apnoeic attack a comparison had to be made with the average flow after apnoea.

It is the practice in this unit to monitor apnoea by ECG detection of bradycardia with an audible alarm threshold set at either 100 or 80 beats per minute depending on whether the resting heart rate is above or below 140 per minute. The observer therefore intervened to terminate apnoea by skin stimulation when the bradycardic threshold was reached. In no case was active pulmonary inflation necessary to terminate apnoea.

\section{Results}

Infants with apnoeic attacks. A total of 47 apnoeic attacks occurring in 9 infants have been analysed. The effect of apnoea on heart rate, BP, and peripheral blood flow has been summarized in Tables 2 and 3, and a typical record is shown in Fig. 1. Cardiovascular changes were not seen before the onset of apnoea.

Apnoea. Apnoea in which circulatory changes occurred could be as short as 5 seconds (Case 8). There was no consistent mode of onset of apnoea as far as breathing was concerned. Most frequently there was evidence of reduced respiratory movement for a few seconds before the onset of apnoea. Alternatively, breathing stopped abruptly without any prior change. Fig. 2 shows the type of episode exhibited by Case 6 in which there was reduced respiratory movement. It was not possible to say whether ventilation stopped or just became reduced but there was nevertheless accompanying bradycardia and fall in peripheral blood flow.

Heart rate. The heart rate fell by a mean $( \pm \mathrm{SD})$ of $43 \% \pm 13 \%$, on average $8 \cdot 6$ seconds $\pm 6 \cdot 3$ (range $2-33 \mathrm{~s})$ after the onset of apnoea, rising on average $4 \cdot 8$ seconds $\pm 4 \cdot 4$ (range $2-16 \mathrm{~s}$ ) after the resumption of breathing. On two occasions the heart rate did not fall until after resumption of breathing. In one infant (Case 5) the heart rate did not start to fall 


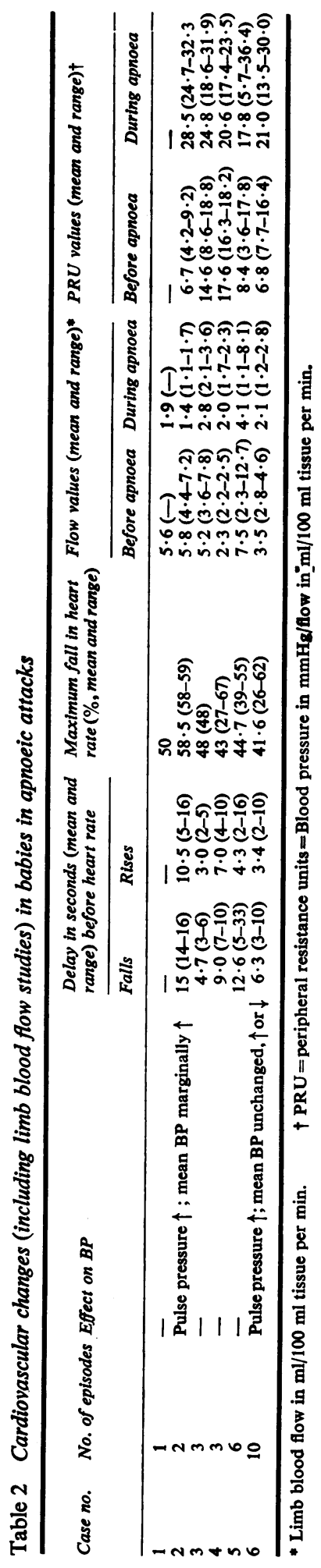


Table 3 Changes in heart rate (HR) and blood pressure (but no blood flow studies) in babies having apnoeic attacks

\begin{tabular}{|c|c|c|c|c|c|c|}
\hline Case no. & $\begin{array}{l}\text { No. of apnoeic } \\
\text { attacks }\end{array}$ & $\begin{array}{l}\text { Duration of apnoea } \\
(s)\end{array}$ & Effect on BP & $\begin{array}{l}\text { Delay before } \\
H R \downarrow(s)\end{array}$ & $\begin{array}{l}\text { Delay before } \\
H R \uparrow(s)\end{array}$ & $\begin{array}{l}\text { Maximum fall } t \\
\text { HR }(\%)\end{array}$ \\
\hline 7 & 4 & $10-14$ & $\begin{array}{l}\text { Pulse pressure } \uparrow \text {; slight fall in } \\
\text { mean BP }\end{array}$ & $0-3$ & $2-3$ & $46-77$ \\
\hline 8 & 11 & $5-40$ & $\begin{array}{l}\text { Pulse pressure } \uparrow \text {; mean BP } \\
\text { usually unchanged but } \\
\text { occasionally } \uparrow\end{array}$ & 4-10 & $2-16$ & $19-58$ \\
\hline 9 & 7 & $15-54$ & $\begin{array}{l}\text { Pulse pressure } \uparrow \text {; mean BP } \\
\text { unchanged }\end{array}$ & $5-14$ & $2-3$ & $8-50$ \\
\hline
\end{tabular}

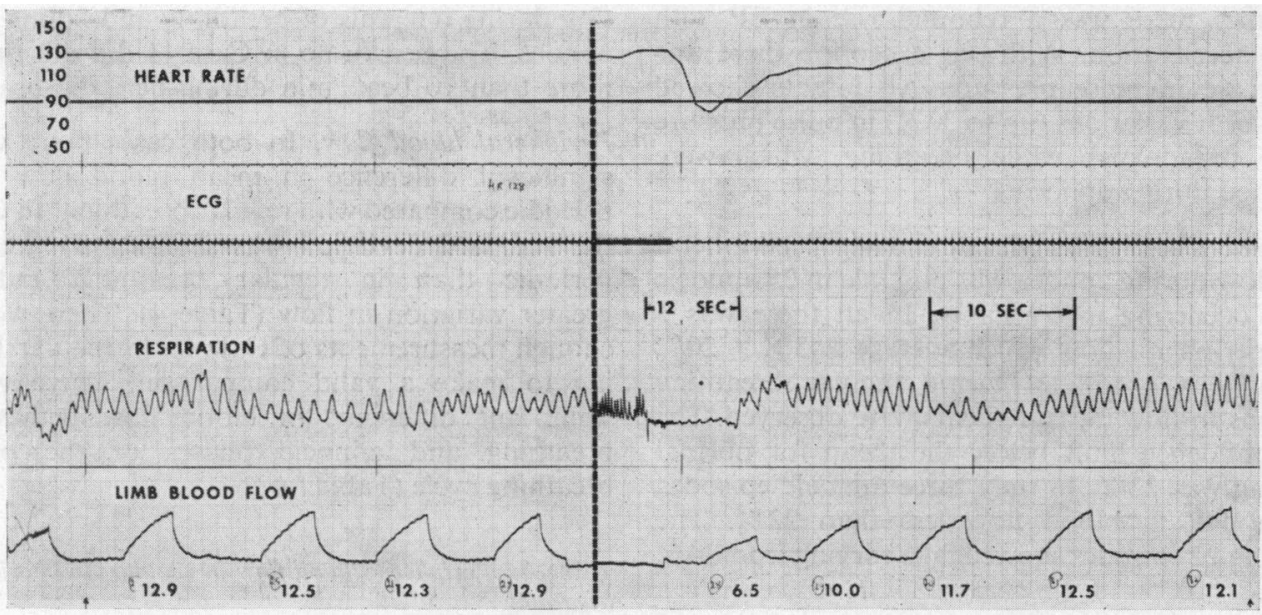

Fig. 1 Case 5. Recording of a typical apnoeic attack. A portion of the trace of 85 seconds' duration has been cut out at the dotted line. Apnoea of 12 seconds' duration is indicated. Note bradycardia and fall in limb flow during apnoea with subsequent recovery. Figures below blood flow slopes $=$ flow in $\mathrm{ml} / 100 \mathrm{ml}$ tissue per min. Note that a small part of the trace to the right of the vertical line is recorded at a slower paper speed.



Fig. 2 Case 6. Episode of hypoventilation associated with marked bradycardia and fall in limb blood flow. In respiration trace note irregular breaths of reduced frequency lasting 18 seconds. In the blood pressure trace note the marked beat-to-beat variation in pulse pressure during regular breathing, a small rise in blood pressure during the episode of hypoventilation, and a larger rebound rise at the time of cardiac acceleration. 
until 33 seconds after the onset of apnoea, and on another occasion the heart rate fell very slowly throughout 40 seconds of apnoea.

Blood pressure. BP was continuously monitored in 34 apnoeic attacks occurring in 6 infants. No consistent changes in mean BP were seen. It could show a small rise (and never more than $10 \mathrm{mmHg}$ $(1 \cdot 33 \mathrm{kPa})$ ), a smaller fall or remain unchanged. Sometimes there was a rebound rise in BP with cardiac acceleration. With one exception there was an increase in pulse pressure. All infants showed beat-to-beat variations (up to $33 \%$ ) in pulse pressure (pulsus paradoxus) while breathing, which were eliminated during apnoea.

Peripheral blood flow. Measurement of peripheral blood flow during apnoea was possible in 25 apnoeic attacks occurring in 6 infants. In all there was a fall in peripheral flow which averaged $43 \% \pm 20 \%$ SD (range 6.1-85\%). During regular breathing variations in flow measurements were observed. The $95 \%$ confidence limit below the mean for normal breathing was $22 \%$. In only three apnoeic episodes was the fall in blood flow less than $22 \%$. The remaining 22 episodes showed falls varying from $24 \%$ to $85 \%$.

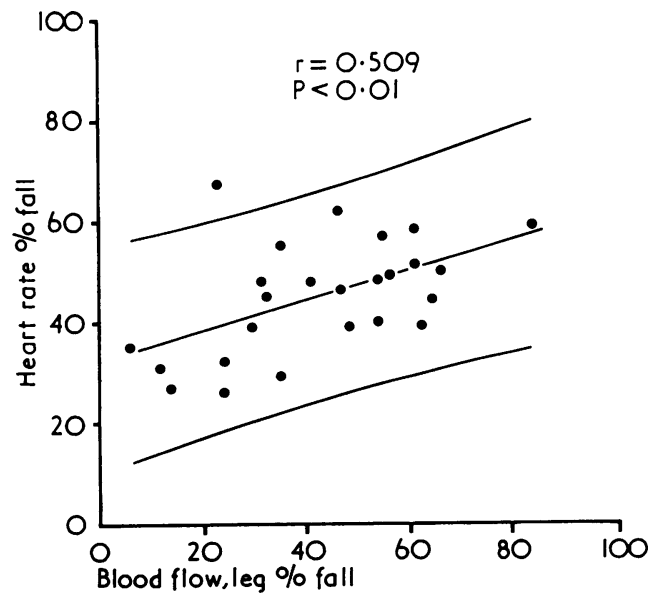

Fig. 3 Correlation of falls in heart rate and limb blood flow occurring in 25 apnoeic attacks in 6 infants. 95\% confidence limits of the measurements are shown.

Babies with periodic breathing. Heart rate and peripheral blood flow were measured in 2 infants with periodic breathing. Case 10 was studied during regular breathing in quiet (non-REM) sleep and when breathing periodically in active (REM) sleep. The periodic breathing consisted of alternate intervals of breathing lasting 5-8 seconds and nonbreathing lasting 5-11 seconds. Case 11 breathed periodically for almost the entire study. She had alternate intervals of breathing and nonbreathing of 7-10 and 5-11 seconds respectively.

Heart rate. Case 10 showed swings in heart rate of up to $\mathbf{4 0}$ beats/min during periodic breathing which were in phase with breathing, the heart rate accelerating during intervals of breathing and falling during apnoea. The heart rate in Case 11 did not fluctuate more than 10 beats/min during periodic breathing.

Peripheral blood flow. In both cases there was no significant difference in mean blood flow during periodic compared with regular breathing. In Case 10 the standard deviation was significantly greater in periodic than in regular breathing, indicating greater variation in flow (Table 4). There were not enough measurements of Case 11 in regular breathing to make a valid comparison. There was no significant difference in blood flow between the breathing and apnoeic phases of the periodic breathing cycle (Table 5).

Table 4 Peripheral blood flow in regular and periodic breathing

\begin{tabular}{llll}
\hline $\begin{array}{l}\text { Case } \\
\text { no. }\end{array}$ & Breathing & $\begin{array}{l}\text { No. of flow } \\
\text { measurements }\end{array}$ & $\begin{array}{l}\text { Mean flow }(\mathrm{ml} / 100 \mathrm{ml} \\
\text { tissue per min } \pm 1 S D)\end{array}$ \\
\hline 10 & Regular & 38 & $3 \cdot 41 \pm 0 \cdot 83$ \\
& Periodic & 32 & $3 \cdot 40 \pm 1 \cdot 38^{*}$ \\
11 & Regular & 4 & $7 \cdot 25 \pm 1 \cdot 56$ \\
& Periodic & 41 & $5 \cdot 81 \pm 0.90$ \\
\hline
\end{tabular}

* Significant, $P<0.001$. Variance ratio test.

Table 5 Comparison of right leg blood flow in breathing and apnoeic phases of periodic breathing

\begin{tabular}{llll}
\hline & \multicolumn{2}{l}{ Mean flow $(\mathrm{ml} / 100 \mathrm{ml}$ tissue per min $\pm 1 S D$} \\
\cline { 2 - 3 } Case no. & Breathing & Apnoea & $P^{*}$ \\
\hline 10 & $4 \cdot 1 \pm 1 \cdot 49$ & $4 \cdot 0 \pm 1 \cdot 78$ & \\
& $\mathrm{n}=7$ & $\mathrm{n}=7$ & $\mathrm{NS}$ \\
11 & $5 \cdot 9 \pm 1 \cdot 0$ & $6 \cdot 3 \pm 0 \cdot 8$ & $\mathrm{NS}$ \\
& $\mathrm{n}=9$ & $\mathrm{n}=12$ & \\
\end{tabular}

* Student's ' $t$ ' test.

\section{Discussion}

Immature infants with gestations as low as $\mathbf{2 7}$ weeks have marked cardiovascular changes in response to apnoea. Apnoea causes bradycardia and peripheral vascular constriction. The effect on BP is slight and variable though pulse pressure rises. The fall in limb blood flow and the bradycardia were significantly correlated $(r=0.509, P<0 \cdot 01)$ (Fig. 3). 
Usually the maximum fall in flow and bradycardia occurred towards the end of a period of apnoea (Fig. 1), but it could occur after the resumption of breathing. The reason for this delayed effect is not clear. Continuous measurement of arterial oxygen tension during apnoea was not available to us and we are therefore not able definitively to ascribe these cardiovascular changes to hypoxia. Similar cardiovascular responses to hypoxia are, however, well established in animals and it has been shown that these responses are mediated primarily by the peripheral chemoreceptors in the dog (Daly and Scott, 1962; Cross et al., 1963; Angell James and Daly, 1969), cat (Downing and Siegel, 1963), rabbit (Chalmers et al., 1967), and fetal lamb (Dawes et al., 1969) during the last third of gestation.

The shortest time interval between onset of apnoea and onset of bradycardia, and between the end of apnoea and cardiac acceleration were both about 2 seconds. This time interval could, however, be as long as 16 seconds and in one instance was 33 seconds, the reason for such variation being unclear. Both a short and a long interval could occur in the same patient (Case 5).

When breathing restarts the bradycardia would be expected to be eliminated either by lung inflation over-riding the primary effect of arterial hypoxia (Daly and Scott, 1962; Angell James and Daly, 1969) or by relief of the hypoxia itself. Cardiac acceleration was sometimes delayed up to 16 seconds after breathing restarted. Despite that period of apparently adequate ventilation, stimulation of the chemoreceptors appeared to persist. Apparently the lung inflation reflex failed to influence bradycardia. Continued hypoxia or hypercapnia of the central nervous system, unless profound, is unlikely to explain the delay since in dogs hypoxia or hypercapnia of the central nervous system produces tachycardia (Downing et al., 1963).

In anaesthetized dogs an inverse relationship has been shown between lung volume and peripheral vascular resistance. Stretch receptors in the lung are a constant source of afferent impulses inhibiting the vasomotor centre (Daly et al., 1967). It might be expected therefore that peripheral blood flow would fluctuate during periodic breathing. In the 2 infants with periodic breathing (Cases 10,11) there were no significant differences in overall limb blood flow during periodic and regular breathing (Table 4). In both infants during periodic breathing there was no difference in flow comparing the apnoeic phases with the breathing phases (Table 5).

Because of the marked fall in heart rate during apnoea there will be a fall in cardiac output which is compensated for by peripheral vasoconstriction. Systemic blood pressure is thus maintained. Under these circumstances cerebral blood flow would at least be maintained and might even be increased, since experimental asphyxia in lambs (Kjellmer et al., 1974) and fetal monkeys (Behrman et al., 1970) has been shown to have this effect. This study therefore suggests a redistribution of blood flow tending to protect the blood supply of the brain and probably other vital organs (e.g. the heart) during the early stages of apnoea.

\section{Conclusions}

From this study of the cardiovascular responses to apnoea and periodic breathing in 11 preterm infants the following conclusions can be drawn. (a) Apnoea was followed by bradycardia and peripheral vasoconstriction. (b) In 2 infants with periodic breathing there was no significant difference in limb blood flow between the breathing and apnoeic phases. (c) Infants of as low as 27 weeks' gestatation have marked cardiovascular responses to chemoreceptor drive. (d) Cardiovascular responses to apnoea may function to preserve blood supply to the brain and other vital organs.

I thank Drs. A. C. Bryan, P. R. Swyer, and B. S. L. Kidd for help, and Miss Antoinette Zitman for assistance with recordings. Supported by grant no. 4-7 from the Ontario Heart Foundation, Toronto, Ontario, Canada.

\section{References}

Alden, E. R., Mandelkorn, T., Woodrum, D. E., Wennberg, R. P., Parks, C. R., and Hodson, A. (1972). Morbidity and mortality of infants weighing less than 1000 grams in an intensive care nursery. Pediatrics, 50, 40-49.

Angell James, J. E., and Daly, M. de B. (1969). Cardiovascular responses in apnoeic asphyxia: role of arterial chemoreceptors and the modification of their effects by a pulmonary vagal inflation reflex. Journal of Physiology, 201, 87-104.

Behrman, R. E., Lees, M. H., Peterson, E. N., de Lannoy, C. W., and Seeds, A. E. (1970). Distribution of the circulation in the normal and asphyxiated fetal primate. American Journal of Obstetrics and Gynecology, 108, 956-969.

Chalmers, J. P., Korner, P. I., and White, S. W. (1967). Local and reflex factors affecting the distribution of peripheral blood flow during arterial hypoxia in the rabbit. Journal of Physiology, 192, 537-548.

Cross, C. E., Rieben, P. A., Barron, C. I., and Salisbury, P. F. (1963). Effects of arterial hypoxia on the heart and circulation: an integrative study. American Journal of Physiology, 205, 963-970.

Daily, W. J. R., Klaus, M., and Meyer, H. B. P. (1969). Apnea in premature infants: monitoring, incidence, heart rate changes, and an effect of environmental temperature. Pediatrics, 43, 510-518.

Daly, M. de B., and Scott, M. J. (1962). An analysis of the primary cardiovascular reflex effects of stimulation of the carotid body chemoreceptors in the dog. Journal of Physiology, 162, 555-573. 
Daly, M. de B., Hazzledine, J. L., and Ungar, A. (1967). The reflex effects of alterations in lung volume on systemic vascular resistance in the dog. Journal of Physiology, 188, 331-351.

Dawes, G. S. (1968). Fetal and Neonatal Physiology, p. 146. Year Book Medical Publishers, Chicago.

Dawes., G. S., Duncan, S. L., Lewis, B. V., Merlet, C. L., Owen-Thomas, J. B., and Reeves, J. T. (1969). Hypoxaemia and aortic chemoreceptor function in foetal lambs. Journal of Physiology, 201, 105-116.

Downing, S. E., and Siegel, J. H. (1963). Baroreceptor and chemoreceptor influences on sympathetic discharge to the heart. American Journal of Physiology, 204, 471-482.

Downing, S. E., Mitchell, J. H., and Wallace, A. G. (1963). Cardiovascular responses to ischemia, hypoxia and hypercapnia of the central nervous system. American Journal of Physiology, 204, 881-887.

Girling, D. J. (1972). Changes in heart rate, blood pressure and pulse pressure during apnoeic attacks in newborn babies. Archives of Disease in Childhood, 47, 405-410.

Grunstein, M. M., Derenne, J. P., and Milic-Emili, J. (1974). Effect of baroreceptor stimulation on the regulation of the depth and frequency of breathing in cats. Physiologist, 17, 234.

Kidd, L., Levison, H., Gemmel, P., Aharon, A., and Swyer, P. R. (1966). Limb blood flow in the normal and sick newborn. American Journal of Diseases of Children, 112 , 402-407.
Kjellmer, I., Hrbek, A., Karlsson, K., Olsson, T., Rhia, M., and Rosen, K. G. (1974). Cerebral reactions during acute hypoxia in the fetal lamb. (Abst.) Critical Care Medicine. 2,55 .

Levison, H., Kidd, B. S. L., Gemmell, P. A., and Swyer, P. R. (1966). Blood pressure in normal full-term and premature infants. American Journal of Diseases of Children, 111, 374-379.

Powers, W. F., and Swyer, P. R. (1975a). Limb blood flow following umbilical arterial catheterization. Pediatrics, 55, 248-256.

Powers, W. F., and Swyer, P. R. (1975b). The peripheral hemodynamic effects of continuous positive transpulmonary pressure breathing in neonates free from cardiorespiratory disease. Pediatrics, 56, 203-207.

Scholander, P. F. (1960). Experimental studies on asphyxia in animals. Oxygen Supply to the Fetus, p. 267, Ed. by J. Walker and A. C. Turnbull. Blackwell, Oxford.

Whitney, J. R. (1949). The measurement of changes in human limb volume by means of a mercury-in-rubber strain gauge. Journal of Physiology, 109, 5P-6P.

Whitney, R. J. (1953). The measurement of volume changes in human limbs. Journal of Physiology, 121, 1-27.

Correspondence to Dr. C. N. Storrs, Department of Paediatrics, Churchill Hospital, Headington, Oxford OX3 7LJ. 